\title{
Sistem Pemantauan Inkubator Bayi Menggunakan Jaringan Wifi dan Berbasis Database
}

\author{
Endah Setyaningsih ${ }^{1}$ \\ Program Studi Teknik Elektro Universitas Tarumanagara \\ Email: endahs@ft.untar.ac.id \\ Tommy ${ }^{1}$ \\ Program Studi Teknik Elektro Universitas Tarumanagara \\ Harlianto Tanudjaja ${ }^{2}$ \\ Program Studi Teknik Elektro Universitas Katolik Atma Jaya \\ Harlianto.tanudjaja@atmajaya.ac.id
}

\begin{abstract}
Baby incubator is very important to keep the newborn's body temperature especially for premature babies. Premature babies is the babies that born less than 37 weeks and has less than 2500 grams body weight. Baby incubator is designed to have a lenght of $70 \mathrm{~cm}$, a width of $40 \mathrm{~cm}$, and a height of $60 \mathrm{~cm}$. The system of baby incubator will automatically turn on or turn off the fan, heater or humidifier in accordance with the range of temperature and humidifier that has been set. The range of humidifier inside the baby incubator is $40 \%-60 \%$. The range of temperature can be set in a Graphical User Interface (GUI). At GUI, user can fill and show babies profile, babies activity, level of baby's bilirubin, and the range of temperature. Those Datas are saved in a database's tables. GUI can show the temperature and humidity of babies incubator in form of graph. Babies monitoring can be done by wireless. There is a monitoring device that can buzz if the baby is crying. This system has a database that can store incubator room temperature-humidity data, baby's temperature, sound counters, biodata, activity, bilirubin and incubator temperature regulation. Can also provide information about the incubator's humidity and baby's temperature on the LCD and GUI and can save the record of the activities carried out by the baby, as well as keep a record of the baby's bilirubin value and turn on the lights automatically according to the bilirubin value input.

Keyword: Baby Incubator; Database; Graphical User Interface; Wireless; Monitoring Device
\end{abstract}

ABSTRAK: Inkubator bayi sangat berperan penting untuk menjaga suhu tubuh bayi baru lahir khususnya bagi bayi prematur. Bayi prematur adalah bayi yang lahir kurang dari 37 minggu dan memiliki berat badan kurang dari 2500 gram. Inkubator bayi yang dirancang memiliki ukuran ruang panjang $70 \mathrm{~cm}$, lebar $40 \mathrm{~cm}$, dan tinggi $60 \mathrm{~cm}$. Sistem dari inkubator bayi ini akan secara otomatis menyalakan atau mematikan kipas, heater atau humidifier sesuai dengan batas suhu dan kelembaban yang telah diatur. Batas kelembaban udara di dalam inkubator bayi adalah sebesar $40 \%$ sampai $60 \%$. Batas suhu inkubator bayi diatur sesuai dengan umur dan berat badan bayi. Pengaturan batas suhu inkubator bayi dapat diatur pada sebuah Graphical User Interface (GUI). Pada GUI, pengguna dapat mengisi dan menampilkan biodata bayi, aktivitas bayi, tingkat bilirubin bayi dan batas suhu inkubator yang diinginkan. Data-data tersebut disimpan pada tabel-tabel yang berada pada sebuah basis data. GUI juga dapat menampilkan suhu dan kelembaban inkubator bayi dalam bentuk grafik. Pemantauan bayi dapat dilakukan secara wireless. Terdapat sebuah alat pemantau yang akan berbunyi apabila bayi menangis. Sistem ini memiliki database yang dapat menyimpan data suhu-kelembaban ruang inkubator, suhu tubuh, counter suara, biodata, aktivitas, bilirubin dan pengaturan temperatur inkubator. Juga dapat memberikan informasi mengenai suhu-kelembaban inkubator dan suhu tubuh bayi pada LCD dan GUI dan dapat menyimpan record aktivitas yang dilakukan bayi, serta menyimpan record nilai bilirubin bayi dan menyalakan lampu secara otomatis sesuai dengan nilai bilirubin yang di-input.

Kata Kunci: Alat Pemantau; Basis Data; Graphical User Interface; Inkubator Bayi; Wireless;

\section{PENDAHULUAN}

$\mathrm{P}$ erkembangan teknologi dibidang kedokteran saat ini semakin pesat, hal ini disebabkan kebutuhan yang semakin banyak di bidang kedokteran yang harus ditunjang dengan kemampuan teknologi. Kemampuan teknologi dapat meliputi adanya perkembangan produk seperti sensor-sensor yang lebih peka dan lebih teliti, juga perkembangan medianya seperti perubahan dari teknologi kabel ke teknologi non kabel (wireless), salah satunya penggunaan jaringan wifi. Adanya teknologi wifi, lebih memberikan keleluwasaan dalam jangkauan jarak dan dapat menyesuaikan dengan adanya perkembangan teknologi dibidang selular. Inkubator merupakan peralatan yang digunakan untuk membantu menangani bayi lahir prematur, terbantu juga dengan adanya perkembangan teknologi yaitu berupa adanya wifi serta sensor ini. Salah satu bantuannya berupa adanya pemantauan bayi oleh seorang perawat yang dapat dilakukan sesuai keberadaan perawat, dan tidak harus memantau secara langsung dihadapan bayi tersebut. Perancangan sistem pemantauan inkubator bayi ini, dilakukan dengan menggunakan wifi, dan berdasarkan database bayi, yang diinfokan melalui sensor-sensor yang diletakkan disekitar bayi

\footnotetext{
${ }^{1}$ Program Studi Teknik Elektro, Universitas Tarumanagara

${ }^{2}$ Program Studi Teknik Elektro Universitas Katolik Atma Jaya
} 
tersebut. Sensor-sensor tersebut antara lain sensor suhu, sensor kelembaban, dan sensor suara. Saat ini belum banyak sistem pemantauan inkubator bayi yang dengan teknologi semacam ini, dan perancangan ini merupakan salah satu penelitian untuk membuat sistem prototipe pemantauan inkubator bayi dengan menggunakan adanya wifi dan berbasis database.

Seorang bayi yang lahir kurang dari 37 minggu dan memiliki berat kurang dari 2500 gram disebut bayi prematur [1]. Bayi yang lahir prematur membutuhkan perawatan intensif karena sangat rentan terhadap penyakit yang sebagian besar disebabkan oleh timbulnya bakteri karena suhu dan kelembaban di sekitar bayi yang tidak normal. Selain itu, bayi dengan kelahiran prematur kurang mampu beradaptasi dengan temperatur lingkungan luar yang mudah berubah. Bayi yang baru lahir juga memiliki resiko terkena penyakit kuning. Secara fisiologis tubuh seseorang memproduksi sel darah merah dan akan membuang atau memecah sel darah merah yang sudah tua. Produk buangan dari proses pemecahan itulah yang disebut bilirubin indirek yang tidak larut dalam air. Bilirubin indirek ini kemudian harus diproses di dalam hati hingga menjadi bilirubin indirek yang larut dalam air. Fungsi organ hati pada bayi yang baru lahir masih belum matang sehingga proses perubahan bilirubin menjadi lambat.

Terapi sinar biru dapat dilakukan untuk mengatasi endapan bilirubin. Terapi ini dapat dilakukan terus menerus pada bayi dalam keadaan telanjang pada ruang inkubator untuk tetap menjaga suhu tubuh bayi. Proses terapi sinar biru dilakukan sesuai dengan tingkat atau kadar bilirubin. Terapi dijalankan selama 2-4 hari pada bayi dengan kadar bilirubin antara $12 \mathrm{mg} / \mathrm{dl} \mathrm{sampai} 14 \mathrm{mg} / \mathrm{dl}$ sesuai perkembangan bayi. Terapi sinar biru dapat berlangsung hingga 1 minggu apabila kondisi kadar bilirubin bayi di atas $15 \mathrm{mg} / \mathrm{dl}[2]$.

Bayi lahir prematur yang diletakkan di inkubator membutuhkan perawatan yang intensif, perawat harus sesering mungkin memantau kondisi bayi. Salah satu caranya adalah dengan mendatangi bayi tersebut, namun kadang-kadang perawat terkendala dengan tugas lain, sehingga tidak mungkin untuk selalu berada di sekitar bayi tersebut. Berdasarkan penelitian sebelumnya disebutkan bahwa, salah satu kesulitan bagi para petugas kesehatan atau perawat yang berada jauh atau tidak berada dalam ruang yang sama dengan keberadaan inkubator bayi untuk melakukan pemantauan kondisi ruang inkubator bayi adalah keharusan bolak-balik dari ruangan sentral ke ruang perawatan atau inkubator bayi [3]. Petugas harus secara rutin bolak-balik ruangan untuk memeriksa kondisi bayi dan inkubator.

Sebelum merealisasi perancangan sistem ini, telah dilakukan beberapa kali survei, tujuannya untuk mengetahui perancangan lain yang telah dilakukan oleh peneliti sebelumnya atau melihat langsung sistem inkubator yang telah ada, dan digunakan oleh beberapa rumah sakit atau pusat kesehatan. Survei pertama dilakukan melalui sebuah sistem pengontrolan suhu dan kelembaban pada inkubator bayi. Sistem ini dirancang oleh Laura Antasia Seserago Lapono agar suhu dan kelembaban pada inkubator bayi dapat dikontrol. Pengontrolan suhu dan inkubator bayi dilakukan secara otomatis dengan menggunakan sebuah mikrokontroler Atmega 8535. Sistem inkubator bayi ini akan secara otomatis menyalakan atau mematikan kipas dan atau pemanas sesuai dengan batas normal dari suhu dan kelembaban udara di dalam inkubator bayi [1]. Alat ini memanfaatkan sensor DHT11 untuk mendeteksi suhu dan kelembaban pada inkubator bayi. Elemen pemanas dan kipas tersedia untuk mengontrol suhu dan kelembaban pada inkubator bayi. Mikrokontroler Atmega8535 berfungsi untuk menerima data suhu dan kelembaban dari sensor DHT11 dan mengaktifkan atau menonaktifkan elemen pemanas dan kipas guna mengatur suhu inkubator yang diinginkan.

Survei kedua dilakukan pada sebuah pengembangan inkubator bayi dan sistem pemantauan remote. Pengembangan dan perancangan sistem ini dilakukan oleh Syahrul. Pada penelitiannya dilakukan pengembangan desain berupa penambahan pemantauan kelembaban ruang inkubator bayi dan juga dilengkapi dengan penginderaan saat bayi kencing [3]. Terdapat dua buah mikrokontroler pada alat ini yang berfungsi sebagai pengirim dan penerima. Terdapat modul YS-1020UB yang berfungsi sebagai pemancar dan penerima data melalui gelombang radio berfrekuensi tinggi. Alat ini memanfaatkan empat buah sensor LM35DZ yang berfungsi mengubah besaran temperatur menjadi besaran listrik. Selain itu, terdapat juga sensor SHT11 yang berfungsi mengubah besaran kelembaban menjadi besaran listrik. Nilai dari sensor LM35DZ dan SHT11 akan ditampilkan di Liquid Crystal Display (LCD) pada mikrokontroler pengirim maupun penerima.

Survei ketiga dilakukan pada sebuah inkubator bayi berbasis mikrokontroler dilengkapi sistem telemetri melalui jaringan RS485. Penelitian inkubator bayi ini dilakukan oleh Roni Wijaya, F. Dalu Setiaji, dan Daniel Santoso. Penelitian yang dilakukan bertujuan merancang dan merealisasikan sebuah inkubator bayi yang memiliki fasilitas lebih baik dibandingkan dengan inkubator sederhana yang dijual di pasaran, dengan harga yang tetap terjangkau[4]. Pada inkubator ini terdapat mikrokontroler Atmega8535 yang berfungsi sebagai pengendali sensor suhu dan kelembaban SHT11. Suhu ruang 
inkubator dapat diatur oleh pengguna antara $28^{\circ} \mathrm{C}-37^{\circ} \mathrm{C}$. Inkubator ini menggunakan elemen pemanas listrik sebagai sumber panas yang digunakan dengan metode on-off. Sistem telemetri berbasis RS 485 juga diimplementasikan pada inkubator ini, sehingga suhu dan kelembaban ruang inkubator dapat dipantau melalui sebuah komputer dari jarak jauh[4]. Berdasarkan hasil pengujian yang dilakukan, dapat dilihat bahwa suhu ruang inkubator dapat dijaga stabil pada kisaran $28^{\circ} \mathrm{C}-37^{\circ} \mathrm{C}$ dengan toleransi maksimal $1{ }^{\circ} \mathrm{C}$. Program aplikasi antarmuka sistem telemetri dapat mengirimkan perintah permintaan data pada inkubator setiap 30 detik kemudian data logger akan mencatat data hasil pengukuran yang diterima dari inkubator setiap lima menit sekali.

Survei keempat dilakukan dengan metode survei lapangan. Survei dilakukan di salah satu rumah sakit besar di Jakarta. Survei ini bertujuan untuk mengetahui inkubator yang digunakan pada rumah sakit umumnya. Rumah sakit ini menggunakan inkubator yang berfungsi untuk mengatur suhu dan kelembaban sesuai dengan kondisi bayi. Suhu pada inkubator yang digunakan dapat diatur sesuai yang diinginkan, namun untuk kelembaban tidak dapat diatur. Inkubator ini juga dilengkapi dengan sensor suhu tubuh untuk mengukur suhu tubuh bayi. Sensor suhu tubuh yang digunakan dalam bentuk probe yang ditempelkan di bagian kanan perut bayi. Inkubator bayi ini tidak dilengkapi dengan lampu biru. Pihak rumah sakit memiliki alat yang terpisah apabila bayi membutuhkan fototerapi. Alat tersebut memiliki lampu biru yang dapat diletakkan di atas inkubator dengan jarak 40-60 cm. Gambar inkubator yang digunakan pada salah satu rumah sakit di Jakarta ini dapat dilihat pada Gambar 1 dan Gambar 2.

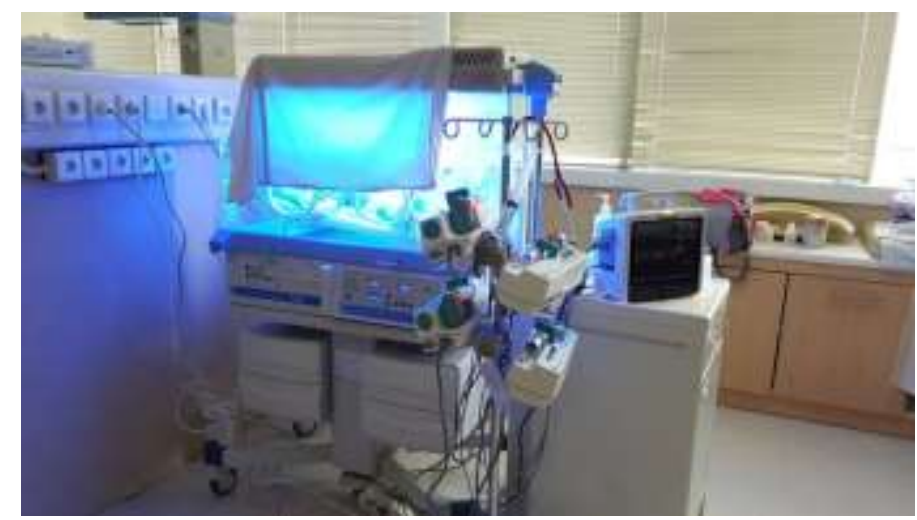

- Gambar 1. Inkubator Bayi yang Digunakan di salah satu rumah sakit di Jakarta

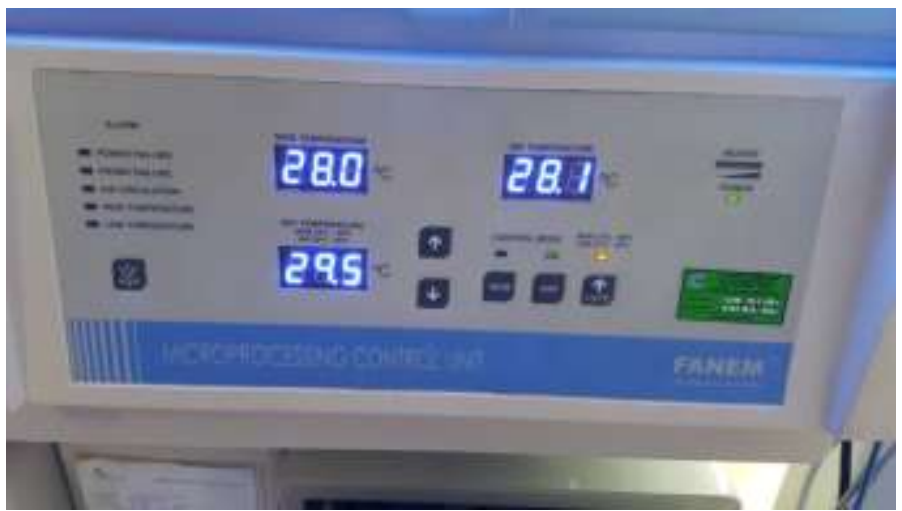

- Gambar 2. Pengaturan Suhu dan Tampilan Informasi Inkubator Bayi.

Perancangan sistem pemantau inkubator bayi memerlukan beberapa modul. Modul yang digunakan dalam rancangan sistem pemantauan inkubator ini adalah:

modul pengukur suhu tubuh, modul pengukur suhu-kelembaban, modul pengukur suara, modul pemroses, modul pengendali suhu-kelembaban inkubator, modul pengaturan lampu biru, modul alat pemantau , database, Graphical User Interface (GUI), dan lampu biru. Sedangkan spesifikasi sistem pemantau inkubator bayi ini yaitu menggunakan sumber tegangan 220 Volt, dimensi: $70 \mathrm{~cm} \mathrm{x} 40 \mathrm{~cm} \mathrm{x}$ $60 \mathrm{~cm}$, pengukuran suhu : $-40^{\circ} \mathrm{C}-80^{\circ} \mathrm{C}$, pengukuran kelembaban : $0 \%-100 \% \mathrm{RH}$, terdapat lampu biru untuk Phototherapy, terdapat database untuk menyimpan data-data bayi dan data dari sensor, dilengkapi dengan alat pemantau, dilengkapi dengan Liquid Crystal Display (LCD), dan inkubator dan alat pemantau dapat terhubung dengan WiFi. 


\section{METODOLOGI}

Perancangan sistem pemantau inkubator bayi ini, tidak hanya membuat sistem pemantauan nya saja, tapi juga membuat box inkubatornya, yaitu dengan ukuran $(70 \times 40 \times 40) \mathrm{cm}$, seperti yang disebutkan dalam spesifikasi. Sistem pemantauan inkubator bayi ini membutuhkan sebuah modul pemroses serta sensor-sensor seperti sensor suhu dan kelembaban yang berguna untuk mengetahui suhukelembaban ruangan inkubator, sensor suhu tubuh untuk mengetahui suhu tubuh bayi, dan sensor suara untuk mendeteksi suara bayi menangis. Suhu dan kelembaban dalam inkubator akan diatur sesuai taraf yang aman bagi bayi tersebut. Selain itu, dibutuhkan lampu biru yang dapat digunakan untuk melakukan fototerapi terhadap bayi yang terkena penyakit bilirubinemia. Nilai suhu-kelembaban ruang dan suhu tubuh bayi dalam inkubator kemudian akan disimpan dalam memori modul pemroses dan dikirim ke database. Ilustrasi sistem pemantauan inkubator bayi dapat dilihat pada Gambar 3.

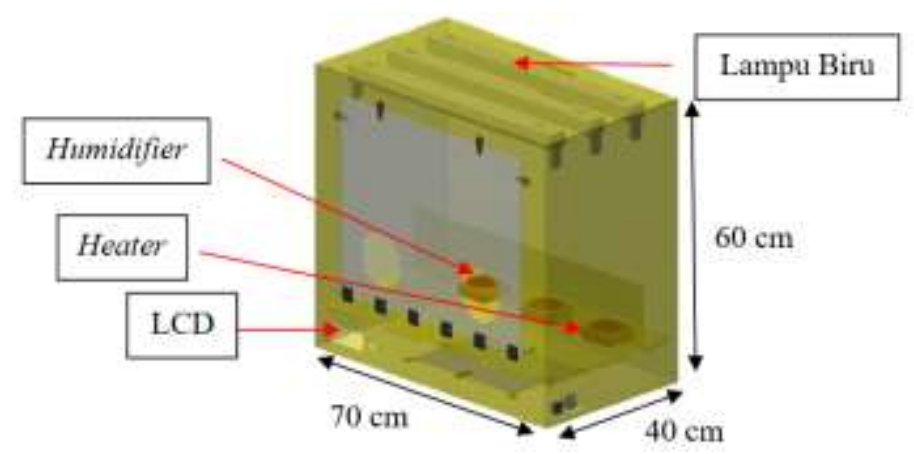

- Gambar 3. Ilustrasi Inkubator yang Dirancang

Sebuah layar akan disediakan untuk menampilkan Graphical User Interface (GUI). GUI pada sistem ini dibutuhkan untuk menampilkan data diri bayi, penjadwalan, meng-input nilai bilirubin bayi, dan menampilkan nilai sensor suhu-kelembaban serta sensor suhu tubuh dari inkubator. Nilai bilirubin yang telah diukur pada seorang bayi dapat di input kemudian akan dilihat kondisi bayi untuk dilakukan fototerapi. Nilai bilirubin tersebut akan dikirim ke database MySQL dan diterima oleh modul pemroses. Nilai bilirubin bayi akan menentukan bayi memerlukan fototerapi atau tidak. Lampu biru pada inkubator akan menyala berdasarkan kadar bilirubin yang di-input. Proses monitoring juga membutuhkan sebuah device yang dirancang untuk memberi peringatan berupa suara buzzer apabila bayi menangis. Pada device ini terdapat sebuah modul pemroses yang terhubung dengan database MySQL. Diagram blok sistem pemantauan inkubator yang dirancang dapat dilihat pada Gambar 4.

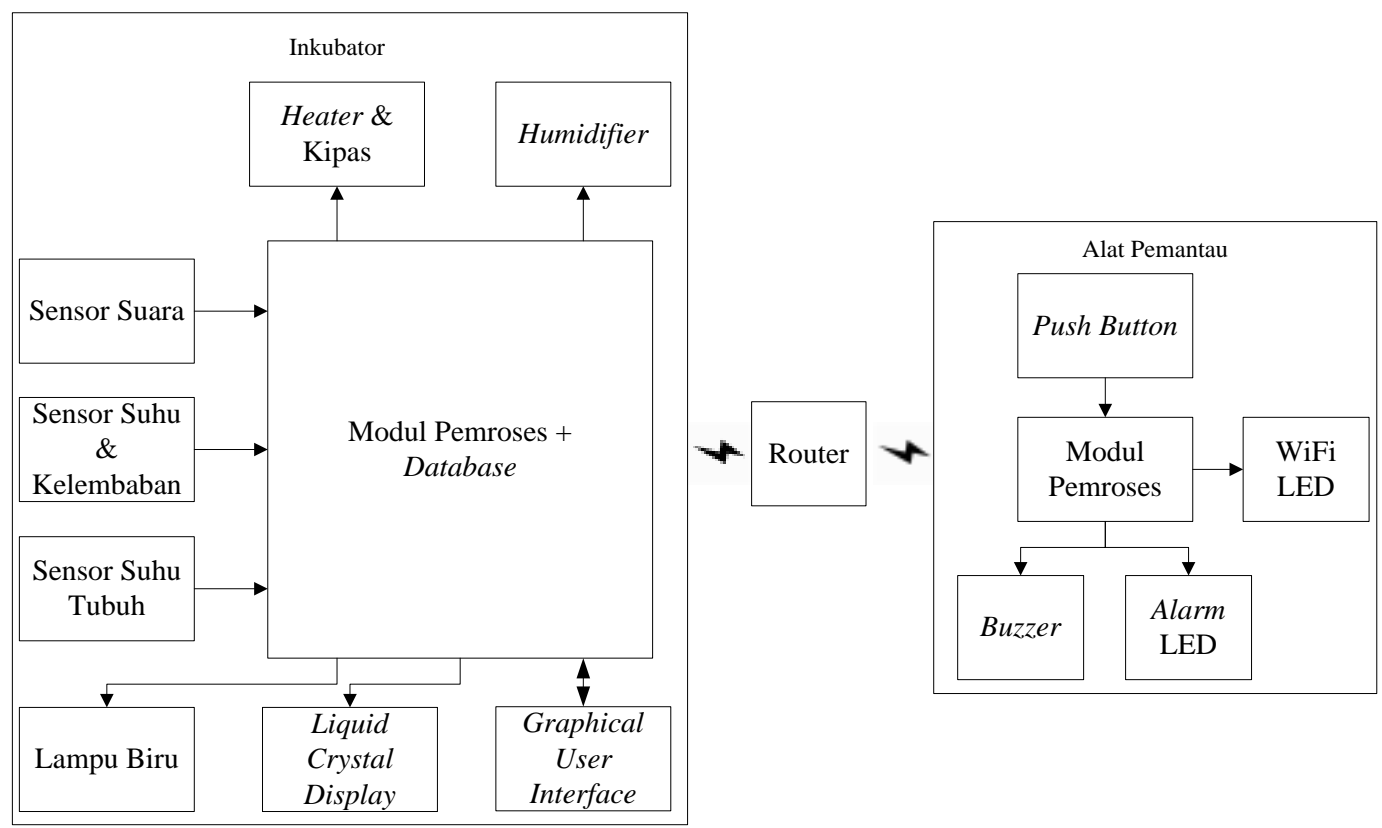

- Gambar 4. Diagram Blok Sistem Pemantauan Inkubator 
Komponen berupa mikrokontroler yang digunakan pada sistem ini adalah mikrokontroler Raspberry Pi 3 Model B sebagai pemroses utama pada Inkubator. Raspberry Pi merupakan sebuah computer single-board yang dibuat oleh Raspberry Pi Foundation. Raspberry Pi adalah sebuah komputer mini yang memiliki fitur yang hampir sama dengan komputer pada umumnya [5]. Raspberry Pi membutuhkan Operating System (OS) agar dapat digunakan. OS ini disimpan dalam sebuah Secure Digital (SD) Card. SD card pada Raspberry Pi digunakan sebagai media penyimpanan data seperti Harddisk pada PC. Ada berbagai jenis Raspberry Pi, salah satunya adalah Raspberry Pi 3 model B. Salah satu alasan penggunaan Raspberry Pi 3 model B adalah terdapatnya pin General Purpose Input/Output (GPIO) sebanyak 26 buah. GPIO tersebut dapat digunakan sebagai input maupun output. Selain itu terdapat $\mathrm{WiFi}$ sehingga dapat terhubung dengan router dengan mudah

Selain itu juga menggunakan mikrokontroler Wemos yang merupakan sebuah mikokontroler pengembangan berbasis modul mikrokontroler ESP8266. Salah satu alasan penggunaan mikrokontroler Wemos dikarenakan memiliki kemampuan untuk menyediakan fasilitas konektifitas WiFi dengan mudah. Mikrokontroler Wemos D1 Mini memiliki 11 pin digital I/O dimana setiap pin memiliki fungsi interrupt, Pulse Width Modulation (PWM), Inter-Integrated Circuit $\left(\mathrm{I}^{2} \mathrm{C}\right)$, dan one-wire kecuali pada pin D0. Mikrokontroler ini memiliki 1 analog input dengan maksimum tegangan sebesar 3,3 Volt. Alasan lain pemilihan mikrokontroler Wemos karena ukuran board mikrokontroler ini hanya sebesar $34,2 \mathrm{~mm}$ x 25,6mm dan beratnya sebesar 3 gram. Raspberry Pi 3 model B dan Wemos D1 Mini dapat dilihat pada Gambar 5.
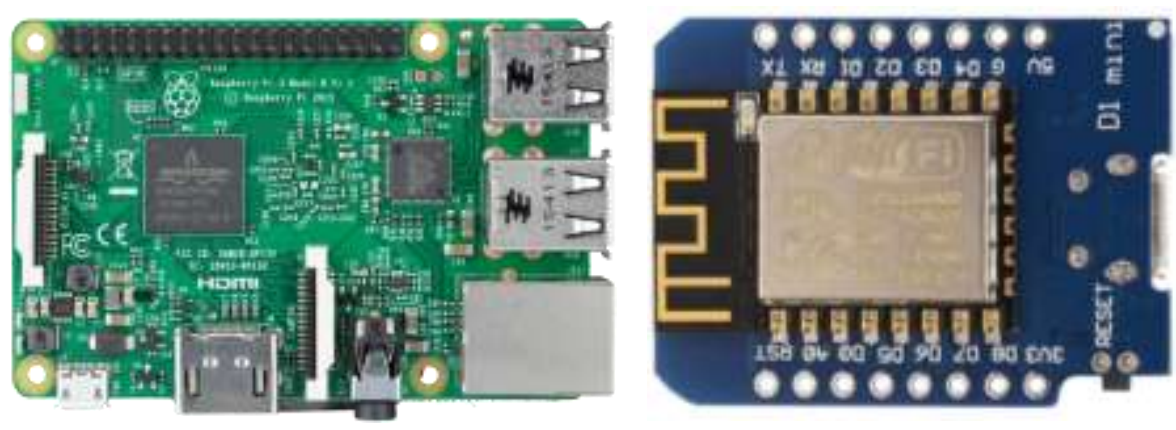

- Gambar 5. Raspberry Pi 3 Model B dan Wemos D1 Mini

Komponen berupa yang dugunakan adalah sensor DHT22 sebagai sensor suhu-kelembaban ruang inkubator. Sensor DHT22 memiliki kemampuan untuk mengukur suhu udara sekaligus kelembaban udara. Jenis sensor yang digunakan adalah kelembaban kapasitif. Pemilihan jenis sensor ini dikarenakan resolusi pengukuran suhu $0,1^{\circ} \mathrm{C}$ dan resolusi pengukuran kelembaban $0,1 \%$. Dimensi ukuran dari sensor yang tidak terlalu besar yaitu 25,1 $\times 15,1 \times 7,7 \mathrm{~mm}$. Akurasi dari sensor ini untuk pengukuran kelembaban udara berkisar 2-5\% dan untuk pengukuran suhu sebesar $\pm 1^{\circ} \mathrm{C}$. Sensor lainnya yaitu sensor suhu DS18B20 pada perancangan ini digunakan untuk mengukur suhu tubuh. Sensor DS18B20 merupakan sensor suhu berbentuk IC. DS18B20 merupakan sensor suhu digital. Pemilihan sensor DS18B20 dalam perancangan ini dikarenakan akurasi sensor untuk pengukuran suhu $\pm 0,5^{\circ} \mathrm{C}$. Sensor DS18B20 merupakan sensor suhu dengan rage pengukuran yang luas. Pengukuran suhu dapat dilakukan dari $-55^{\circ} \mathrm{C}-125^{\circ} \mathrm{C}$. Sensor ini memerlukan sumber tegangan sebesar 3-5,5V untuk bekerja. Sensor DS18B20 memiliki 3 buah pin yaitu GND, data, dan VCC.

\section{HASIL PENGUJIAN DAN ANALISIS}

Pengujian sistem bertujuan mengetahui kinerjanya dan memastikan setiap modul sesuai dengan yang dirancang dan bekerja sesuai dengan fungsinya. Pengujian selain dilakukan pada pengujian setiap modul, juga dilakukan pengujian modul software. Pengujian modul software meliputi modul GUI dan modul database. Pengujian selanjutnya melalui beberapa kasus dan setiap kasus dicatat hasilnya.

Modul pengukur suhu tubuh diuji kerja sensornya. Pengujian modul pengukur suhu tubuh dilakukan dengan membandingkan hasil pengukuran sensor dengan termometer air raksa. Perhitungan dilakukan dengan menggunakan rumus kesalahan relatif, yaitu 
Kesalahan Relatif $=\delta n: \frac{X n-X}{X} x 100 \%$ dengan Xn merupakan nilai pengukuran sensor dan $\mathrm{X}$ merupakan nilai standar. Hasil pengujian dapat dilihat pada Tabel 1.

- Tabel 1. Pengujian Modul Pengukur Suhu Tubuh

\begin{tabular}{|c|c|c|c|}
\hline No. & $\begin{array}{c}\text { Pengukuran dengan } \\
\text { Sensor }\left({ }^{\circ} \mathrm{C}\right)\end{array}$ & $\begin{array}{c}\text { Pengukuran dengan } \\
\text { Termometer Air Raksa } \\
\left({ }^{\circ} \mathrm{C}\right)\end{array}$ & $\begin{array}{c}\% \text { Kesalahan } \\
(\%)\end{array}$ \\
\hline 1 & 35,2 & 35,5 & 0,85 \\
\hline 2 & 35,8 & 36 & 0,56 \\
\hline 3 & 35,38 & 35,5 & 0,34 \\
\hline 4 & 35,2 & 35,4 & 0,57 \\
\hline 5 & 35,43 & 35,6 & 0,49 \\
\hline
\end{tabular}

Pada pengujian ini, termometer air raksa dianggap sebagai standar perbandingan alat ukur. Hasil pengujian tersebut menunjukkan bahwa perbedaan pengukuran menggunakan modul pengukur suhu tubuh tidak jauh berbeda dengan termometer air raksa. Setiap pengukuran memiliki presentase kesalahan di bawah 1\% dan telah sesuai dengan datasheet DS18B20 yang menyatakan tingkat akurat sensor sebesar $\pm 0,5 \%$. Dengan demikian dapat dikatakan bahwa sensor yang digunakan pada modul sudah akurat.

Pengujian modul pengukur suhu-kelembaban inkubator bertujuan untuk memastikan kerja pengukur suhu dan kelembaban yang digunakan. Pemroses Raspberry Pi diprogram sesuai dengan sensor dan waktu pengukuran yang ditentukan. Hasil pengukuran suhu dan kelembaban dibaca pada Raspberry Pi menggunakan Python 2.7. Hasil pengukuran tersebut dibandingkan dengan hasil pengukuran alat ukur digital yaitu sebuah thermo-hygrometer. Perhitungan dilakukan dengan menggunakan rumus kesalahan relatif, yaitu Kesalahan Relatif $=\delta n: \frac{X n-X}{X} x 100 \%$ dimana Xn merupakan nilai pengukuran sensor dan X merupakan nilai standar. Pengujian untuk modul pengukur suhu-kelembaban Inkubator dapat dilihat pada Tabel 2.

- Tabel 2. Pengujian Modul Pengukur Suhu-Kelembaban

\begin{tabular}{|c|c|c|c|c|c|}
\hline \multicolumn{2}{|c|}{$\begin{array}{c}\text { Pengukuran Sensor Suhu- } \\
\text { Kelembaban }\end{array}$} & \multicolumn{2}{c|}{$\begin{array}{c}\text { Pengukuran Termometer } \\
\text { dan Hygrometer Digital }\end{array}$} & \multicolumn{2}{c|}{$\%$ Kesalahan } \\
\hline Suhu $\left({ }^{\circ} \mathrm{C}\right)$ & $\begin{array}{c}\text { Kelembaban } \\
(\% \mathrm{RH})\end{array}$ & Suhu $\left({ }^{\circ} \mathrm{C}\right)$ & $\begin{array}{c}\text { Kelembaban } \\
(\% \mathrm{RH})\end{array}$ & Suhu (\%) & $\begin{array}{c}\text { Kelembaban } \\
(\%)\end{array}$ \\
\hline 29,8 & 43,2 & 30 & 43,8 & 0,67 & 1,34 \\
\hline 30,5 & 43,7 & 30,6 & 44,1 & 0,33 & 0,91 \\
\hline 31,9 & 49,4 & 32,1 & 50 & 0,62 & 1,2 \\
\hline 33,2 & 51,8 & 33,6 & 52,5 & 1,19 & 1,33 \\
\hline
\end{tabular}

Pada pengujian ini, termometer dan hygrometer digital dengan merk X tipe KW06-281 milik dianggap sebagai standar perbandingan alat ukur. Hasil pengujian tersebut menunjukkan bahwa perbedaan pengukuran menggunakan modul pengukur suhu-kelembaban tidak jauh berbeda dengan termometer dan hygrometer analog. Setiap pengukuran memiliki presentase kesalahan $\pm 1 \%$ dan telah sesuai dengan datasheet DHT22 yang menyatakan tingkat akurat sensor sebesar $\pm 1 \%$. Dengan demikian dapat dikatakan bahwa sensor yang digunakan pada modul sudah akurat.

Pengujian modul pendeteksi suara bertujuan untuk memastikan bahwa sensor suara yang digunakan dapat bekerja dengan baik. Hasil deteksi suara dibaca pada Raspberry Pi menggunakan Python 2.7. Pengujian dilakukan sebanyak 4 kali dengan jarak pengujian yang berbeda-beda dan 2 jenis suara yang berbeda yang berasal dari Smartphone. Pengujian untuk modul pendeteksi suara dapat dilihat pada Tabel 3. 
- Tabel 3. Pengujian Modul Pendeteksi Suara

\begin{tabular}{|c|c|c|c|}
\hline Pengujian Ke- & Jarak Pengujian & \multicolumn{2}{|c|}{ Jenis Suara } \\
\cline { 3 - 4 } & $(\mathrm{cm})$ & Tepuk Tangan & Tangisan Bayi \\
\hline 1 & 10 & Terdeteksi & Terdeteksi \\
\hline 2 & 25 & Terdeteksi & Terdeteksi \\
\hline 3 & 50 & Terdeteksi & Terdeteksi \\
\hline 4 & 75 & Terdeteksi & Terdeteksi \\
\hline
\end{tabular}

Hasil pengujian di atas menunjukkan bahwa sensor suara dapat bekerja dengan baik. Sensor suara dapat mendeteksi suara yang berasal dari Smartphone dengan jenis suara tepuk tangan dan tangisan bayi dengan jarak pengujian $10 \mathrm{~cm}-75 \mathrm{~cm}$. Pengujian dilakukan pada rentang $10 \mathrm{~cm}-75 \mathrm{~cm}$ karena posisi antara sensor suara dengan kepala bayi berada pada jarak $\pm 50 \mathrm{~cm}$. Dengan demikian dapat dikatakan bahwa sensor suara telah bekerja dengan baik.

Pengujian modul pengendali suhu-kelembaban inkubator bertujuan untuk memastikan rangkaian modul pengendali suhu-kelembaban dapat bekerja dengan baik. Pengujian dilakukan dengan menggunakan Python 2.7 untuk mengaktifkan heater, humidifier dan kipas. Pin dari Raspberry Pi dihubungkan ke setiap relay dimana masing-masing relay terhubung dengan heater, humidifier atau kipas. Pengujian pertama dilakukan untuk mengetahui bahwa heater, humidifier dan kipas dapat diaktifkan berdasarkan kondisi pin dari Raspberry Pi yaitu high $( \pm 3,3 \mathrm{~V})$ dan low $(0 \mathrm{~V})$. Heater, humidifier dan kipas akan menyala ketika kondisi pin dari Raspberry Pi adalah high $( \pm 3,3 \mathrm{~V})$, sebaliknya heater, humidifier dan kipas akan mati ketika kondisi pin dari Raspberry Pi adalah low (0V). Selanjutnya dilakukan pengujian pada heater untuk mengetahui perbandingan kenaikan tingkat suhu terhadap waktu serta pengujian pada kipas untuk mengetahui perbandingan penurunan tingkat suhu terhadap waktu. Tujuan dari pengujian ini adalah untuk mengetahui perkiraan lama waktu yang dibutuhkan sistem untuk menghangatkan ruang inkubator dan menurunkan suhu mencapai titik tertentu. Hasil pengujian dapat dilihat pada Tabel 4 dan Tabel 5.

- Tabel 4. Pengujian Lama Kenaikan Suhu Ruang Inkubator

\begin{tabular}{|c|c|}
\hline $\begin{array}{c}\text { Suhu Ruang Inkubator } \\
\left({ }^{\circ} \mathrm{C}\right)\end{array}$ & $\begin{array}{c}\text { Waktu } \\
(\mathrm{s})\end{array}$ \\
\hline 25 & 0 (Suhu awal) \\
\hline 27 & 133 \\
\hline 29 & 280 \\
\hline 31 & 555 \\
\hline 33 & 792 \\
\hline 35 & 1078 \\
\hline
\end{tabular}

Tabel 5. Pengujian Lama Penurunan Suhu Ruang Inkubator

\begin{tabular}{|c|c|}
\hline $\begin{array}{c}\text { Suhu Ruang Inkubator } \\
\left({ }^{\circ} \mathrm{C}\right)\end{array}$ & $\begin{array}{c}\text { Waktu } \\
(\mathrm{s})\end{array}$ \\
\hline 31 & 0 (Suhu Awal) \\
\hline 29,5 & 193 \\
\hline 28,5 & 440 \\
\hline
\end{tabular}

Hasil pengujian ini menunjukkan bahwa waktu yang diperlukan ruang inkubator dari $25^{\circ} \mathrm{C}$ mencapai suhu $35^{\circ} \mathrm{C}$ adalah 1078 detik atau sekitar 17 menit. Pengujian dilakukan pada rentang suhu $25^{\circ} \mathrm{C}-35^{\circ} \mathrm{C}$ dikarenakan suhu inkubator yang dibutuhkan bayi berada pada rentang suhu tersebut. Hal ini dapat dilihat pada Lampiran XIII Pengaturan Suhu Inkubator RS Royal Taruma. Sebelum penggunaan maka inkubator perlu dinyalakan terlebih dahulu agar dapat mencapai suhu yang sesuai dengan kebutuhan bayi. Berdasarkan hasil pengujian Tabel 4.6 menunjukkan bahwa waktu yang diperlukan untuk menurunkan suhu ruang inkubator dari $31^{\circ} \mathrm{C}$ mencapai $28,5^{\circ} \mathrm{C}$ adalah 440 detik atau sekitar 7 menit. Hasil yang didapatkan menunjukkan bahwa kipas dapat menurunkan suhu ruang inkubator. Pengujian Humidifier juga dilakukan untuk mengetahui bahwa humidifier dapat meningkatkan kelembaban ruang. Waktu yang diperlukan ruang inkubator dari kelembaban 40,5\% mencapai 56\% adalah 398 detik atau sekitar 6 menit. Hasil yang didapatkan menunjukan bahwa humidifier yang digunakan dapat menaikkan kelembaban ruang inkubator. 
Pengujian modul alat pemantau bertujuan untuk memastikan rangkaian modul pengaturan lampu biru dapat berkerja dengan baik. Pengaturan lampu biru dilakukan dengan menggunakan Python 2.7 untuk mengaktifkan dan mematikan lampu biru tersebut. Pin dari Raspberry Pi dihubungkan ke relay yang kemudian dihubungkan secara langsung ke lampu biru. Pengujian pertama dilakukan untuk mengetahui bahwa lampu biru dapat menyala berdasarkan kondisi pin dari Raspberry Pi. Hasil pengujian pada kondisi pin mikrokontroler low, lampu biru tidak menyala dan pada kondisi pin mikrokontroler High, lampu biru menyala. Hasil pengujian ini, menunjukkan bahwa modul pengaturan lampu biru bekerja dengan baik. Saat pin Raspberry Pi diberikan kondisi low maka lampu biru akan mati, sebaliknya apabila pin Raspberry Pi diberikan kondisi high maka lampu biru akan menyala. Selanjutnya, kondisi low dan high diatur berdasarkan kondisi yang diberikan berdasarkan input dari GUI. Pada GUI diberikan input nilai bilirubin yang berbeda sebanyak 4 kali. Pengujian dilakukan kembali berdasarkan input nilai bilirubin pada GUI yang hasil pengujiannya dapat dilihat pada Tabel 6. Pengujian lampu biru menunjukkan bahwa lampu biru dapat bekerja dengan baik berdasarkan input dari GUI. Pengguna dapat melakukan input nilai bilirubin dari GUI untuk menyalakan atau mematikan lampu biru. Apabila nilai bilirubin di atas 12 maka lampu biru akan menyala, sebaliknya apabila nilai bilirubin di bawah atau sama dengan 12 maka lampu biru akan mati.

- Tabel 6. Pengujian Modul Pengendali Lampu Biru dengan Input dari GUI

\begin{tabular}{|c|c|}
\hline $\begin{array}{c}\text { Nilai Bilirubin yang Di-input } \\
(\mathrm{mg} / \mathrm{dL})\end{array}$ & $\begin{array}{c}\text { Kondisi Lampu } \\
\text { (Menyala/Tidak) }\end{array}$ \\
\hline 10 & Tidak Menyala \\
\hline 11 & Tidak Menyala \\
\hline 12 & Tidak Menyala \\
\hline 13 & Menyala \\
\hline 14 & Menyala \\
\hline
\end{tabular}

Pengujian modul alat pemantau bertujuan untuk mengetahui bahwa alat pemantau dapat bekerja dengan baik. Alat pemantau diprogram untuk membaca data counter dari file PHP server dan menampilkannya pada serial monitor. Selain itu, Buzzer pada alat pemantau diprogram agar berbunyi apabila data yang terbaca nilainya melebihi 100. Pengujian pertama dilakukan untuk memastikan bahwa buzzer bekerja dengan baik. Selanjutnya, pengujian alat pemantau dilakukan dengan membaca data pada server dan menampilkannya pada serial monitor. Selain itu, data yang diperoleh akan menentukan buzzer menyala atau tidak. Tabel pengujian alat pamantau dapat dilihat pada Tabel 7. Hasil pengujian menunjukkan bahwa alat pemantau sudah dapat bekerja dengan baik. Alat pemantau dapat membaca data pada server dan menampilkannya pada serial monitor. Selain itu, buzzer dapat diaktifkan data yang diterima lebih dari 100. Angka 100 merupakan standar yang dibuat pada sistem ini. Tidak terjadi kesalahan dalam pembacaan data di server maupun kondisi untuk membunyikan buzzer.

\begin{tabular}{|c|c|c|} 
— Tabel 7. Pengujian Alat Pemantau \\
\begin{tabular}{|c|c|c|}
\hline Pengujian Ke- & Data yang Diterima & Buzzer (Berbunyi/Tidak) \\
\hline 1 & 52 & Tidak Berbunyi \\
\hline 2 & 124 & Berbunyi \\
\hline 3 & 78 & Tidak Berbunyi \\
\hline 4 & 102 & Berbunyi \\
\hline 5 & 111 & Berbunyi \\
\hline
\end{tabular}
\end{tabular}

Pengujian GUI dilakukan untuk mengetahui kinerjanya. Pengujian pertama dilakukan dengan melakukan perpindahan halaman. Pengujian dilakukan sebanyak 5 kali untuk masing-masing halaman. Pertama, GUI akan melakukan perpindahan dari halaman awal ke halaman pengubah data diri bayi dan kembali lagi ke halaman awal. Kedua, GUI akan melakukan perpindahan dari halaman awal ke halaman penjadwalan dan kembali lagi ke halaman awal. Ketiga, GUI akan melakukan perpindahan dari halaman awal ke halaman phototherapy dan kembali lagi ke halaman awal. Keempat, GUI akan melakukan perpindahan dari halaman awal ke halaman inkubator.

Pengujian selanjutnya adalah pengujian pengiriman data dari GUI ke database. Pada halaman pengubah data diri bayi, data diri akan diisi dan dikirim ke database. Data diri yang dikirim akan terlihat pada tabel database biodata. Pada halaman penjadwalan, data aktivitas bayi dan keterangan akan diisi 
dan dikirim ke database. Data aktivitas dan keterangan yang dikirim dapat dilihat pada tabel database aktivitas. Pada halaman phototherapy, nilai bilirubin dan risk factor akan diisi untuk dikirim ke database dan hasil pengiriman dapat dilihat pada tabel bilirubin_test. Pengujian terakhir adalah pembacaan tabel database pada GUI. Pada halaman penjadwalan, terdapat tabel yang akan menampilkan tabel aktivitas dari database. Demikian juga pada halaman phototherapy terdapat tabel yang akan menampilkan tabel bilirubin_test dari database. Pada halaman inkubator, terdapat grafik yang menampilkan nilai suhu dan kelembaban ruang dari tabel monitoring. Pengujian halaman pengubah data diri bayi seperti pada Gambar 6 dan pengujian halaman awal, seperti Gambar 7.

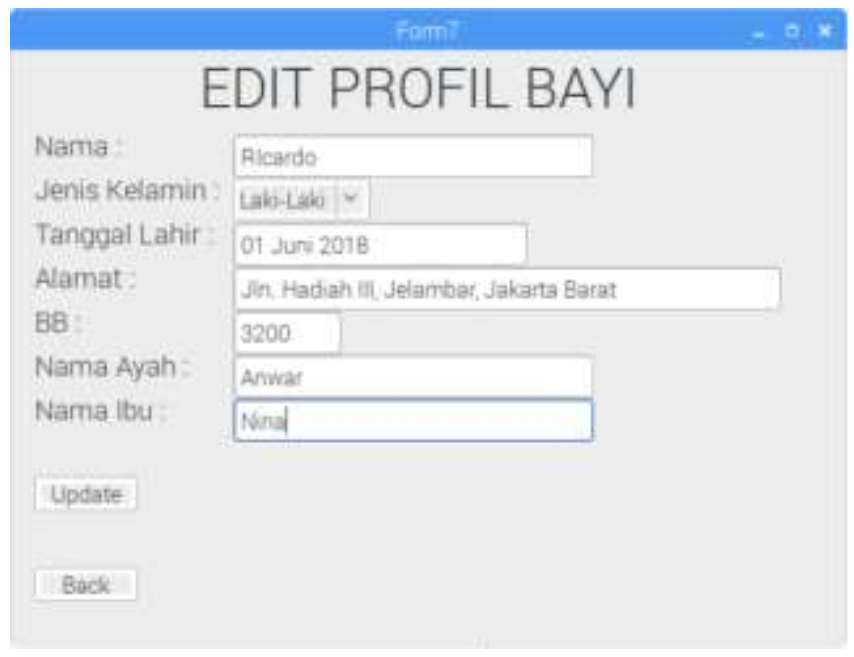

- Gambar 6. Pengujian Halaman Pengubah Data Diri Bayi

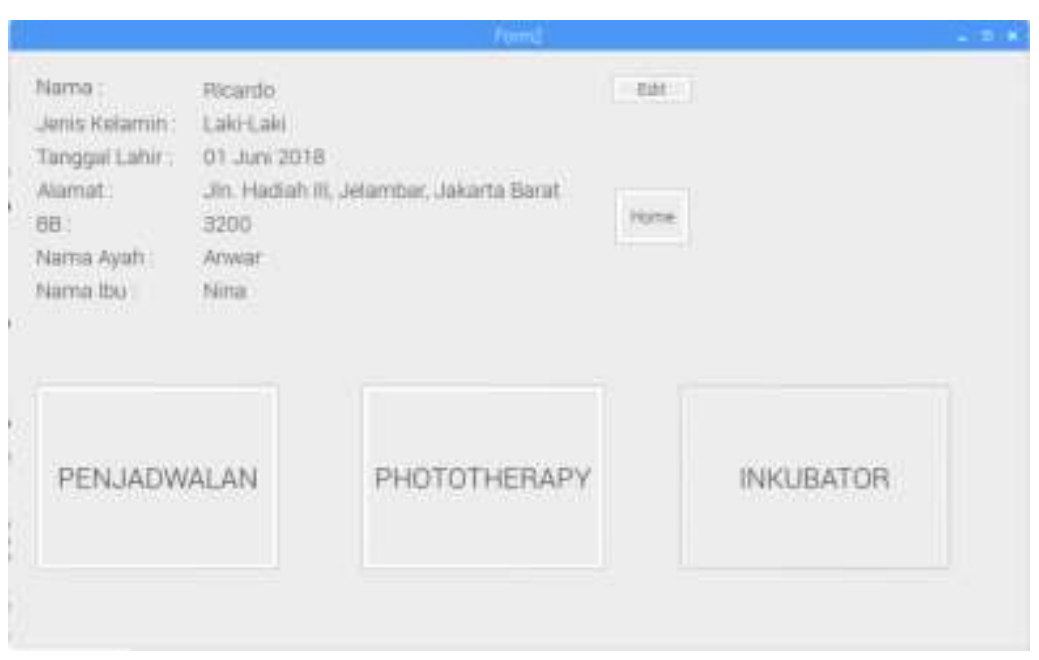

- Gambar 7. Pengujian Halaman Awal

Pengujian sistem dilakukan dengan membagi dalam beberapa kasus dan setiap kasus tersebut dilihat hasilnya. Kasus pertama adalah alat dapat mengendalikan suhu dan kelembaban inkubator serta melakukan pengaturan temperatur yang diinginkan. Pengguna meng-input nilai temperatur inkubator yang diinginkan terlebih dahulu kemudian heater, humidifier, dan kipas pada inkubator bekerja untuk menyesuaikan temperatur dan kelembaban inkubator. Kasus kedua yang diuji adalah melakukan monitoring suhu-kelembaban inkubator. Monitoring ini dilakukan melalui GUI dengan menampilkan grafik suhu dan kelembaban pada inkubator. Kasus ketiga yang diuji adalah melakukan input aktivitas bayi. Input aktivitas bayi dilakukan pada GUI dengan memilih jenis aktivitas yang dilakukan yaitu buang air besar, buang air kecil dan minum susu. Setelah memilih jenis aktivitas, pengguna dapat menulis keterangan yang diperlukan dan melakukan input ke database. Tabel aktivitas dari database akan ditampilkan pada GUI. Kasus keempat yang diuji adalah pengaturan lampu biru. Pengguna terlebih dahulu meng-input nilai bilirubin pada GUI. Apabila nilai bilirubin pada GUI dibawah atau sama dengan 12 maka lampu pada inkubator tidak menyala. Apabila nilai bilirubin pada GUI diatas 12 maka lampu biru pada Inkubator akan menyala. 
Kasus kelima yang diuji adalah alat pemantau. Counter sensor suara dikirim ke database terlebih dahulu dan mikrokontroler pada alat pemantau membaca dan melakukan pengecekan terhadap nilai counter tersebut. Apabila counter diatas 100 maka buzzer pada alat pemantau akan berbunyi, sebaliknya apabila counter dibawah atau sama dengan 100 maka buzzer alat pemantau tidak akan berbunyi. Beberapa kasus dan hasil pengujian dapat dilihat pada Tabel 8. Berdasarkan hasil pengujian sistem, dapat disimpulkan bahwa alat yang dirancang sesuai dengan tujuan yaitu dapat mengendalikan suhukelembaban inkubator sesuai input dari pengguna, melakukan monitoring dengan menampilkan grafik suhu-kelembaban inkubator, melakukan input aktivitas serta menampilkannya pada GUI, melakukan pengaturan lampu biru sesuai input pengguna dari GUI, dan alat pemantau dapat memberi peringatan apabila counter di atas 100 yang menandakan bayi menangis.

- Tabel 8. Pengujian Sistem

\begin{tabular}{|c|c|}
\hline \multicolumn{2}{|c|}{ Kasus dan Hasil Uji Sistem } \\
\hline Kasus & Hasil Uji Sistem \\
\hline $\begin{array}{l}\text { Pengguna meng-input nilai temperatur } \\
\text { ruang inkubator dengan nilai } 31^{\circ} \mathrm{C} \text { pada } \\
\text { GUI. }\end{array}$ & $\begin{array}{l}\text { Heater dan kipas dinding aktif untuk } \\
\text { menstabilkan suhu antara } 30^{\circ} \mathrm{C}-32^{\circ} \mathrm{C} \text {, } \\
\text { Heater akan dimatikan apabila suhu di } \\
\text { atas } 32^{\circ} \mathrm{C} \text { dan kipas akan dimatikan } \\
\text { apabila suhu dibawah } 30^{\circ} \mathrm{C} \text {. } \\
\text { Humidifier akan bekerja untuk } \\
\text { menyesuaikan kelembaban di antara } \\
40 \%-60 \% \text {. }\end{array}$ \\
\hline $\begin{array}{l}\text { Pengguna memasuki halaman Inkubator } \\
\text { pada GUI dan menekan tombol refresh } \\
\text { secara berkala. }\end{array}$ & $\begin{array}{l}\text { Pada halaman GUI dapat ditampilkan } \\
\text { grafik suhu dan kelembaban masing- } \\
\text { masing sebanyak } 20 \text { data terbaru dari } \\
\text { database. Tampilan grafik akan di- } \\
\text { update apabila tombol refresh ditekan. }\end{array}$ \\
\hline $\begin{array}{l}\text { Pengguna memasuki halaman aktivitas } \\
\text { pada GUI dan melakukan pemilihan } \\
\text { aktivitas yang dilakukan bayi dan mengisi } \\
\text { kolom keterangan. }\end{array}$ & $\begin{array}{l}\text { Pada halaman aktivitas dapat } \\
\text { ditampilkan tabel aktivitas-aktivitas } \\
\text { serta keterangan dari aktivitas yang } \\
\text { telah di-input oleh pengguna, } \\
\text { aktivitas yang dilakukan bayi seperti } \\
\text { minum susu, buang air besar dan } \\
\text { buang air kecil, seperti tampilan pada } \\
\text { Gambar } 8 \text {. }\end{array}$ \\
\hline $\begin{array}{l}\text { Pengguna memasuki } \quad \text { halaman } \\
\text { phototherapy pada GUI dan melakukan } \\
\text { input nilai bilirubin. }\end{array}$ & $\begin{array}{l}\text { Lampu biru pada inkubator menyala } \\
\text { ketika pengguna meng-input nilai } \\
\text { bilirubin di atas } 12 \mathrm{mg} / \mathrm{dL} \text {. } \\
\text { Pada halaman phototherapy ditampilkan } \\
\text { tabel record bilirubin yang telah di-input, } \\
\text { seperti tampilan pada Gambar } 9 \text {. }\end{array}$ \\
\hline $\begin{array}{l}\text { Didalam inkubator diletakkan smartphone } \\
\text { yang mengeluarkan suara tangisan bayi. }\end{array}$ & $\begin{array}{l}\text { Alat pemantau akan membunyikan } \\
\text { buzzer secara berulang sampai pengguna } \\
\text { mematikannya dengan menekan tombol } \\
\text { pada alat pemantau. }\end{array}$ \\
\hline
\end{tabular}




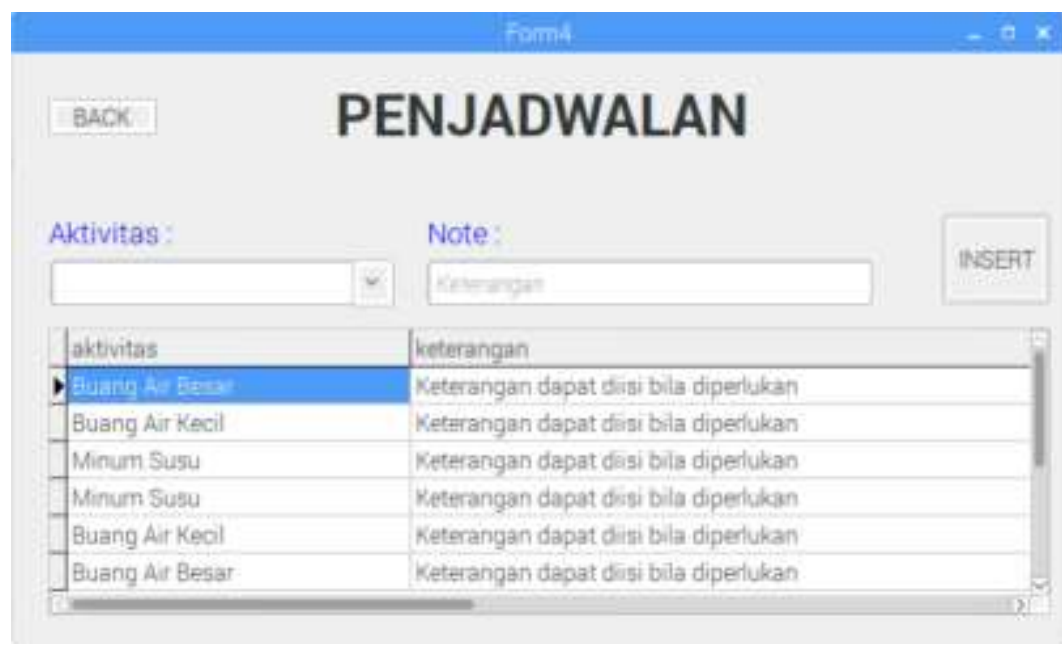

- Gambar 8. Pengujian Halaman Aktivitas Bayi

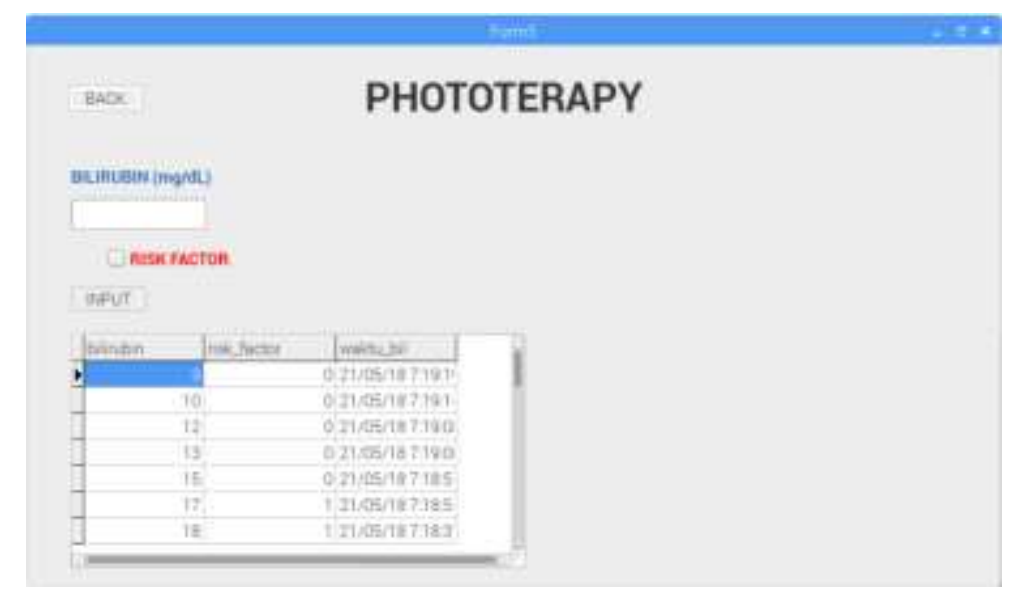

- Gambar 9. Pengujian Halaman Phototherapy

\section{KESIMPULAN}

Kesimpulan sistem pemantauan inkubator bayi dengan jaringan WiFi dan database adalah sistem ini memiliki database yang dapat menyimpan data suhu-kelembaban ruang inkubator, suhu tubuh, counter suara, biodata, aktivitas, bilirubin dan pengaturan temperatur inkubator. Sistem ini dapat memberikan informasi mengenai suhu-kelembaban inkubator dan suhu tubuh bayi pada LCD dan GUI. Sistem ini dapat menyimpan record aktivitas yang dilakukan bayi seperti minum susu, buang air besar dan buang air kecil. Sistem ini dapat menyimpan record nilai bilirubin bayi serta menyalakan lampu secara otomatis sesuai dengan nilai bilirubin yang di-input. Sistem ini memiliki alat pemantau untuk memberi peringatan berupa buzzer apabila bayi menangis.

\section{DAFTAR PUSTAKA}

[1] L.A.S Lapono, Sistem Pengontrolan Suhu dan Kelembaban pada Inkubator Bayi, Vol. 1, No. 1, Jurnal Fisika Sains dan Aplikasinya, pp. 12-17.

[2] Deherba : Terapi Sinar Biru untuk Bayi Kuning, https://www.deherba.com/terapi-sinar-biruuntuk-bayi-kuning.html

[diakses : 15 November 2017]

[3] Syahrul, Pengembangan Inkubator Bayi dan Sistem Pemantauan Remotte, Vol. 6, No. 2, Jurnal Tekno Insentif Kopwil4, pp. 9-17.

[4] R. Wijaya, F.D Setiaji, D. Santoso, Inkubator Bayi Berbasis Mikrokontroler Dilengkapi Sistem Telemetri Melalui Jaringan Rs 485, Vol. 12, No. 1, Techne Jurnal Ilmiah Elektronika, pp. 75-90.

[5] HMTE UNS : Sejarah Raspberry Pi, http://hmte.ft.uns.ac.id/artikel/sejarah-raspberry-pi/ [diakses pada tanggal 05 mei 2018] 